\title{
Segurança no Ato Transfusional: Tendências das Teses e Dissertações Brasileiras
}

\author{
Christiani Andrea Marquesini Rambo, ${ }^{1}$ Tânia Solange Bosi de Souza Magnago, ${ }^{2}$ \\ Bruna Xavier Morais, ${ }^{2}$ Oclaris Lopes Munhoz, ${ }^{2}$ Daniela Buriol, ${ }^{2}$ \\ Vivian De Franceschi Brondani ${ }^{2}$
}

\section{RESUMO}

Objetivo: identificar e caracterizar as tendências das teses e dissertações brasileiras acerca da segurança no ato transfusional. Método: revisão narrativa da literatura, realizada em fevereiro de 2020, a partir das produções disponíveis no Catálogo de Teses e Dissertações da Coordenação de Aperfeiçoamento de Pessoal de Nível Superior, utilizando a palavra-chave "ato transfusional". Foram incluídos estudos que contemplavam estratégias para a melhoria da segurança no ato transfusional. Resultados: o corpus desta revisão foi constituído por sete estudos. Observou-se como tendência dissertações desenvolvidas em instituições públicas, da Região Sudeste, com ano de defesa predominante em 2019 e pesquisas que envolveram profissionais de enfermagem. Quanto ao objeto de estudo, foi possível elencar duas categorias: conhecimento dos profissionais de saúde para atuação nos procedimentos hemoterápicos e utilização e/ou elaboração de ferramentas para segurança no ato transfusional. Conclusão: a falta de conhecimento dos profissionais sobre algumas fases dos procedimentos transfusionais, constitui-se em uma ameaça à segurança dos pacientes. A utilização de ferramentas educativas e listas de verificação para todas as etapas do procedimento é imprescindível para que sejam desenvolvidas com o máximo de segurança.

Palavras-chave: Segurança do paciente; segurança transfusional; transfusão de sangue; medicina transfusional; enfermagem.

\section{SECURITY IN TRANSFUSION ACT: TRENDS IN BRAZILIAN THESES AND DISSERTATIONS}

\section{ABSTRACT}

Objective: identify and characterize the trends of Brazilian theses and dissertations about safety in the transfusion act. Method: narrative review of the literature, carried out in February 2020, based on the productions available in the Catalog of Theses and Dissertations of the Coordination for the Improvement of Higher Education Personnel, using the keyword "transfusion act". Studies that included strategies to improve safety in the transfusion act were included. Results: the corpus of this review consisted of seven studies. It was observed as a tendency dissertation developed in public institutions, in the southeast region, with a predominant year of defense in 2019 and research involving nursing professionals. As for the object of study, it was possible to list two categories: knowledge of health professionals to work in blood therapy procedures and use and/or development of tools for safety in the transfusion act. Conclusion: the professionals' lack of knowledge about some stages of transfusion procedures constitutes a threat to patient safety. The use of educational tools and checklists for all stages of the procedure is essential for them to be developed with maximum security.

Keywords: Patient safety; blood safety; blood transfusion; transfusion medicine; nursing.

RECEBIDO EM: 8/5/2020

MODIFICAÇÕES SOLICITADAS EM: 24/4/2021

ACEITO EM: 28/6/2021

\footnotetext{
${ }^{1}$ Autora correspondente. Universidade Federal de Santa Maria - UFSM, Hospital Universitário de Santa Maria - Serviço de Hemoterapia. Av. Roraima, no 1000, Cidade Universitária - Bairro Camobi. Santa Maria/RS, Brasil. CEP 97105-170. http:// lattes.cnpq.br/7112815036382050. https://orcid.org/0000-0001-6428-9657. chrisamr@hotmail.com

2 Universidade Federal de Santa Maria - UFSM. Santa Maria/RS, Brasil.
} 


\section{INTRODUÇÃO}

Atualmente, a administração de hemocomponentes é um dos procedimentos clínicos mais prescritos. É reconhecida como uma estratégia para vários tratamentos, transplantes, quimioterapias e cirurgias ${ }^{1}$. $\mathrm{O}$ ato transfusional é um dos momentos mais críticos para a segurança do paciente ${ }^{2}$. Ele compreende os procedimentos realizados desde a prescrição médica até a instalação do hemocomponente no receptor e sua monitorização. Mesmo, portanto, que se garanta a segurança do produto sanguíneo proveniente dos hemocentros, o ato transfusional, por ser um processo complexo, com várias etapas, envolvendo profissionais da saúde de diversas categorias, implica em riscos ${ }^{3}$. $O$ ato transfusional apresenta potencial para erros em alguns pontos críticos, como coleta da amostra, decisão médica de transfundir e administração do hemocomponente à beira do leito ${ }^{3-4}$.

Por isso, diversas iniciativas influenciaram diretamente a criação de estratégias para melhorar a segurança na assistência em âmbito mundial. O Brasil também se engajou nessa missão. Os pioneiros em promover medidas para a segurança do paciente foram os órgãos e serviços responsáveis por transfusões de sangue e os serviços de controle de infecção relacionados ao cuidado em saúde e anestesia ${ }^{5}$.

Em 2013, oficializou-se o Programa Nacional de Segurança do Paciente (PNSP), que contemplou estratégias e ações de gestão de risco para as diversas atividades desenvolvidas nos serviços de saúde. Entre estas, incluíram-se as ações referentes à segurança na prescrição, uso e administração de sangue e hemocomponentes ${ }^{6}$. Além do PNSP, para a segurança do processo hemoterápico utilizam-se a regulamentação da RDC $34 / 2014^{7}$ e a Portaria de Consolidação no $5^{8}$. Estas determinam as condições sanitárias para serviços que desenvolvem atividades relacionadas ao ciclo produtivo do sangue humano, componentes e procedimentos transfusionais, além de regulamentar as condições técnicas dos procedimentos hemoterápicos ${ }^{7-8}$.

Dada a complexidade para a garantia da segurança transfusional, faz-se necessário o controle de qualidade nas várias etapas inter-relacionadas que compõem o ciclo do sangue. Isso compreende as atividades executadas desde a doação até a administração do hemocomponente ${ }^{9}$. Nessa situação, a segurança do paciente depende da segurança do produto sanguíneo e do processo clínico de transfusão, ou seja, do ato transfusional como um todo9. Diante disso, percebe-se que a desatenção quanto aos riscos ligados à produção, ao armazenamento e à confiabilidade dos doadores pode causar dano à qualidade e à segurança do sangue ${ }^{10}$.

A alta demanda por hemocomponentes exige parâmetros rígidos de qualidade e segurança em todo o processo transfusional, a fim de minimizar os riscos de falhas técnicas ${ }^{11}$. A segurança nas transfusões é uma das prioridades mundiais. Dados dos principais sistemas de hemovigilância mostram que mais de $80 \%$ dos eventos notificados são em decorrência de falhas humanas ${ }^{12}$. O Serious Hazards of transfusion (SHOT) reportou 1283 near miss no ano de 2016, posto que 264 destes poderiam ter resultado em transfusão incompatível se não tivessem sido detectados ${ }^{13}$. 
No Brasil, ainda não estão disponíveis dados sobre os erros relacionados ao processo transfusional, uma vez que foram incorporados ao sistema de notificação somente em $2016^{14}$. A partir das reações transfusionais notificadas, no entanto, percebe-se que foram contabilizadas 267 reações hemolíticas imunológicas de 2007 a $2015^{14}$. Essa reação ocorre por incompatibilidade do sistema ABO de grupos sanguíneos e pode estar associada a erros no ato transfusional, geralmente por identificação incorreta do paciente, por troca de amostras para testes pré-transfusionais ou de bolsas de hemocomponentes. Nesse contexto, o investimento em pesquisas de tendências sobre a segurança no ato transfusional se faz relevante, pois permite a identificação de modelos de investigação adotados nas teses e dissertações, bem como evidencia lacunas existentes para futuras prioridades de pesquisa e aprimoramento de ações na prática transfusional.

Diante do exposto, tem-se como pergunta de pesquisa: Qual a tendência das teses e dissertações brasileiras acerca da segurança no ato transfusional? Com isso, objetivou-se identificar e caracterizar as tendências das teses e dissertações brasileiras acerca da segurança no ato transfusional.

\section{MÉTODO}

Trata-se de uma revisão narrativa da literatura. Esse tipo de estudo possibilita aprofundar o conhecimento científico sobre determinada temática ${ }^{15}$. A coleta de dados ocorreu em fevereiro de 2020, na base de dados do Catálogo de Teses e Dissertações da Coordenação de Aperfeiçoamento de Pessoal de Nível Superior (Capes), disponível on-line e em regime de domínio público ${ }^{16}$.

Com vistas a contemplar a questão de revisão, utilizou-se como estratégia a palavra-chave "ato transfusional" no campo de busca, sem delimitar intervalo temporal. Salienta-se que, para os resumos não disponíveis na plataforma on-line, buscou-se na biblioteca da instituição de origem da pesquisa.

Para a seleção das teses e dissertações e de programas de Pós-Graduação tanto acadêmicos quanto profissionais, considerou-se a inclusão de estudos que contemplassem estratégias para a melhoria da segurança no ato transfusional. Os estudos, cujas temáticas estavam vinculadas à produção, à indicação clínica de hemocomponentes e a testes imuno-hematológicos, foram excluídos. $\mathrm{Na} \mathrm{Fi-}$ gura 1 consta o fluxograma das etapas de seleção.

Figura 1 - Fluxograma das etapas de seleção das teses e dissertações para compor o corpus final. Santa Maria, RS, Brasil, 2020

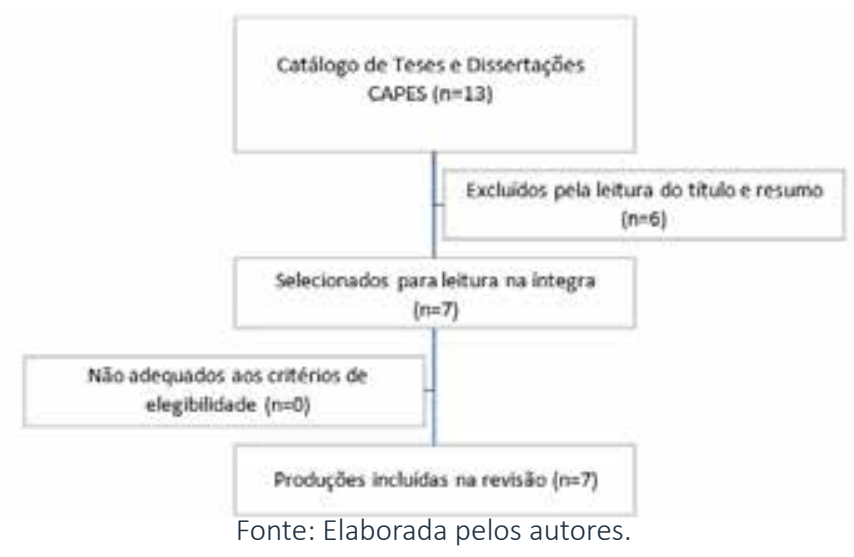

Editora Unijuí - Revista Contexto \& Saúde - ISSN 2176-7114 - v. 21, n. 44, out./dez. 2021 
Localizaram-se 13 publicações (teses e dissertações). Após a leitura dos títulos e resumos, excluíram-se 6 estudos por não contemplarem a temática em tela. Com isso, 7 publicações acadêmicas foram analisadas (Figura 1).

A partir disso, procedeu-se a observação das características gerais dos estudos, tais como ano de defesa, região brasileira onde se defendeu o estudo, instituição, grau acadêmico, delineamento metodológico e população do estudo. Esses dados foram organizados em planilhas do software Microsoft Excel ${ }^{\circ}$ e analisados por estatística descritiva das variáveis.

Em seguida, prosseguiu-se com a análise dos resumos e textos na íntegra. Apreciaram-se os objetivos, resultados obtidos e conclusões para agrupamento dos estudos por semelhança metodológica e de objeto de estudo. Os dados descritivos foram apresentados por meio de frequências absolutas (n) e relativas (\%). Ressalta-se que não foi utilizada técnica qualitativa específica para tratamento dos dados.

Em relação aos aspectos éticos, este estudo respeitou a Lei de Direitos Autorais $n=9.610 / 98$, preservando o direito dos autores por meio de referência de autoria das obras citadas ${ }^{17}$.

\section{RESULTADOS}

A partir da análise e síntese do corpus do estudo ( $n=7)$, foi possível extrair as principais características das teses e dissertações acerca da segurança no ato transfusional (Quadro 1).

Quadro 1 - Quadro sinóptico com as principais características das produções científicas a respeito da segurança no ato transfusional. Santa Maria, RS, Brasil, 2020

\begin{tabular}{|c|c|c|c|}
\hline Autor/Ano & Objetivo & $\begin{array}{l}\text { Instituição/ } \\
\text { Região }\end{array}$ & Método \\
\hline $\begin{array}{l}\text { Vieira, } \\
2019^{18}\end{array}$ & $\begin{array}{l}\text { Construir um checklist } \\
\text { para segurança } \\
\text { transfusional beira-leito }\end{array}$ & $\begin{array}{l}\text { Universidade } \\
\text { Federal de } \\
\text { Juiz de Fora/ } \\
\text { Sudeste }\end{array}$ & $\begin{array}{l}\text { Delineamento: estudo metodológico } \\
\text { População: enfermeiros, médicos, } \\
\text { farmacêuticos e biomédicos } \\
\text { Técnica de coleta dos dados: comitê } \\
\text { de especialistas }\end{array}$ \\
\hline $\begin{array}{l}\text { Cherem, } \\
2015^{19}\end{array}$ & $\begin{array}{l}\text { Identificar e analisar o } \\
\text { saber do enfermeiro } \\
\text { da Unidade de Terapia } \\
\text { Intensiva Neonatal } \\
\text { acerca do processo de } \\
\text { hemotransfusão. }\end{array}$ & $\begin{array}{l}\text { Universidade } \\
\text { Federal } \\
\text { Fluminense/ } \\
\text { Sudeste }\end{array}$ & $\begin{array}{c}\text { Delineamento: estudo descritivo } \\
\text { exploratório } \\
\text { População: profissionais de } \\
\text { enfermagem } \\
\text { Técnica de coleta de dados: } \\
\text { entrevista }\end{array}$ \\
\hline $\begin{array}{l}\text { Tavares, } \\
2013^{20}\end{array}$ & $\begin{array}{l}\text { Analisar o conhecimento } \\
\text { dos profissionais da } \\
\text { equipe de enfermagem } \\
\text { sobre a instalação de } \\
\text { hemocomponente, } \\
\text { identificação de reação } \\
\text { transfusional e condutas } \\
\text { a serem adotadas ante a } \\
\text { reação transfusional. }\end{array}$ & $\begin{array}{l}\text { Universidade } \\
\text { Federal do } \\
\text { Triângulo } \\
\text { Mineiro/ } \\
\text { Sudeste }\end{array}$ & $\begin{array}{l}\text { Delineamento: estudo transversal } \\
\text { População: profissionais de } \\
\text { enfermagem } \\
\text { Técnica de coleta de dados: } \\
\text { questionário }\end{array}$ \\
\hline
\end{tabular}




\begin{tabular}{|c|c|c|c|}
\hline $\begin{array}{l}\text { Kropf, } \\
2018^{4}\end{array}$ & $\begin{array}{l}\text { Avaliar o impacto da } \\
\text { implantação de uma } \\
\text { equipe transfusional } \\
\text { e da busca ativa por } \\
\text { reações transfusionais } \\
\text { nas atividades de } \\
\text { hemovigilância e na } \\
\text { segurança transfusional } \\
\text { em um Núcleo de } \\
\text { Hemoterapia localizado } \\
\text { em um hospital geral. }\end{array}$ & $\begin{array}{l}\text { Universidade } \\
\text { de São Paulo } \\
\text { (Ribeirão } \\
\text { Preto)/Sudeste }\end{array}$ & $\begin{array}{l}\text { Delineamento: estudo comparativo } \\
\text { (antes e depois) } \\
\text { População: técnicos de laboratório } \\
\text { Técnica de coleta de dados: análise } \\
\text { documental }\end{array}$ \\
\hline $\begin{array}{l}\text { Silva, } \\
2019^{21}\end{array}$ & $\begin{array}{l}\text { Construir um checklist } \\
\text { para a Sistematização } \\
\text { da Assistência de } \\
\text { Enfermagem na } \\
\text { monitorização do } \\
\text { procedimento de } \\
\text { hemotransfusão na } \\
\text { unidade intensiva } \\
\text { coronariana. } \\
\end{array}$ & $\begin{array}{l}\text { Universidade } \\
\text { Federal de } \\
\text { Santa Catarina/ } \\
\text { Sul }\end{array}$ & $\begin{array}{c}\text { Delineamento: estudo descritivo } \\
\text { exploratório } \\
\text { População: profissionais de } \\
\text { enfermagem } \\
\text { Técnica de coleta de dados: } \\
\text { entrevista }\end{array}$ \\
\hline $\begin{array}{c}\text { Bezerra, } \\
2017^{3}\end{array}$ & $\begin{array}{l}\text { Construir e validar um } \\
\text { checklist para transfusão } \\
\text { sanguínea em crianças. }\end{array}$ & \begin{tabular}{|c|} 
Universidade \\
Federal do \\
Ceará/Nordeste
\end{tabular} & $\begin{array}{l}\text { Delineamento: estudo metodológico } \\
\text { População: profissionais de } \\
\text { enfermagem } \\
\text { Técnica de coleta de dados: comitê } \\
\text { de especialistas }\end{array}$ \\
\hline $\begin{array}{c}\text { Negraes, } \\
2014^{11}\end{array}$ & \begin{tabular}{|} 
Investigar os principais \\
riscos existentes à \\
segurança em medicina \\
transfusional nas unidades \\
de terapia intensiva (UTI).
\end{tabular} & $\begin{array}{l}\text { Universidade } \\
\text { Federal de } \\
\text { Rondônia/ } \\
\text { Norte }\end{array}$ & $\begin{array}{l}\text { Delineamento: estudo transversal } \\
\text { População: médicos e profissionais } \\
\text { de enfermagem } \\
\text { Técnica de coleta de dados: } \\
\text { questionário, simulação e análise } \\
\text { documental }\end{array}$ \\
\hline
\end{tabular}

Fonte: Elaborada pelos autores.

Dentre os estudos selecionados, todos eram dissertações ( $n=7 ; 100 \%)$ provenientes de mestrados profissionais $(n=4 ; 57,1 \%)$ produzidos em universidades públicas ( $n=7)$, posto que a maioria foi desenvolvida em instituições federais $(n=6 ; 85,7 \%)$. Verificou-se que a região Sudeste $(n=4 ; 57,1 \%)$ é a que mais desenvolve pesquisa na temática. Quanto ao ano de defesa, 2019 teve o maior percentual de estudos ( $n=2 ; 28,5 \%)$. Em relação ao delineamento, os estudos descritivos exploratórios ( $n=2 ; 28,5 \%$ ), os transversais ( $n=2 ; 28,5 \%$ ) e os metodológicos $(n=2 ; 28,5 \%)$ prevaleceram. Ao analisar a população pesquisada, maior percentual envolve a equipe de enfermagem ( $n=4 ; 57,1 \%)$.

Quanto à utilização das palavras-chave/descritores, observou-se o uso de 24 diferentes denominações. Entre estas destacam-se o descritor "transfusão de sangue" ( $n=3)$ e seus sinônimos: "transfusão sanguínea" $(n=2)$ e "transfusão de componentes sanguíneos" ( $n=1)$ foram os mais utilizados em seis dissertações. "Enfermagem", "Reação transfusional", "Segurança do paciente" e "Checklist" foram mencionados duas vezes cada. "Segurança do sangue" e o sinônimo "segurança transfusional" somados também tiveram dois registros. Os demais contaram com uma referência.

No que se refere ao objeto de estudo das dissertações, verificou-se que seguiram distintos direcionamentos, sendo possível estabelecer duas categorias. 
Na primeira, três estudos $(42,9 \%)$ dissertaram sobre o conhecimento dos profissionais de saúde para atuação nos procedimentos hemoterápicos. Na segunda, os estudos ( $n=4 ; 57,1 \%)$ discorreram sobre a utilização e/ou elaboração de ferramentas para melhorar a segurança no ato transfusional com importante destaque à construção de checklist ( $n=3 ; 42,9 \%$ ).

A partir dos principais resultados e conclusões dos estudos, desenvolveram-se duas categorias, descritas a seguir.

\section{Conhecimento dos profissionais acerca do ato transfusional}

As três dissertações que compõem esta categoria avaliaram o conhecimento dos profissionais (médicos e equipe de enfermagem) acerca dos procedimentos envolvidos na transfusão de hemocomponentes. Apontou-se que a maioria dos profissionais já recebeu orientação ou capacitação para administração de produtos sanguíneos e estes se sentem seguros para atuação nesse processo. Ao ser avaliado o conhecimento referente à etapa pré-transfusional, transfusional e sobre complicações imediatas, no entanto, observou-se um escore geral de acertos baixo $(52,7 \%)^{20}$.

Dentre os cuidados de enfermagem elencados pelos profissionais nas etapas pré, peri e pós-transfusional, destacam-se: o encaminhamento da requisição de transfusão; conferência das bolsas de hemocomponente; verificação dos sinais vitais antes, durante e após a transfusão; conduta diante das reações transfusionais, notificações, descarte das bolsas de hemocomponente e evolução das ações realizadas ${ }^{19}$. Observou-se, com isso, que os profissionais apresentam certo grau de conhecimento, contudo não executam alguns itens conforme as exigências da legislação vigente, tais como conferência da prescrição de hemocomponente; identificação adequada do paciente e da amostra de sangue; conferência de todos os dados da etiqueta da bolsa de sangue; conduta adequada perante reações transfusionais; descarte dos resíduos do procedimento; e registro e documentação de todo processo ${ }^{11,19}$. Ainda, verificou-se que $40 \%$ dos tubos de amostras de sangue estavam identificados de maneira não adequada ${ }^{11}$.

Em contrapartida, para alguns cuidados, o conhecimento demonstrado foi considerado satisfatório. Pode-se citar o acompanhamento do paciente nos primeiros dez minutos da infusão, aferição dos sinais vitais tanto no início quanto ao término da infusão, assim como manter o acesso venoso para medicações em caso de reação ${ }^{19}$.

Quanto à avaliação do conhecimento dos médicos, verificou-se que a maioria das prescrições de hemocomponentes não continha os dados mínimos de identificação preenchidos. Além disso, com relação à indicação da transfusão, $20,1 \%$ das indicações de concentrados de hemácias foram classificadas como sem indicação e $41,3 \%$ com indicação adequada, mas com dose exagerada. No que se refere às prescrições de plasma e plaquetas, 50,6\% e 23,2\% destas foram classificadas como sem indicação, respectivamente ${ }^{11}$.

Nesse contexto, os estudos identificaram as principais dificuldades dos profissionais com relação às etapas do ato transfusional. Observaram que há comprometimento da segurança do paciente submetido a transfusões, haja vis-

Editora Unijuí - Revista Contexto \& Saúde - ISSN 2176-7114 - v. 21, n. 44, out./dez. 2021 
ta o conhecimento insuficiente dos profissionais para atuar nesse procedimento ${ }^{11,19-20}$. A fim de melhorar tal cenário, as publicações indicam a necessidade de intervenções como atividades educativas (educação continuada ou material expositivo), criação de sistemas de hemovigilância e confecção de protocolos, manuais e checklist para reduzir os riscos à segurança hemoterápica ${ }^{11,20}$.

\section{Utilização e/ou elaboração de ferramentas para segurança no ato transfusional}

Os quatro estudos desta categoria trouxeram ferramentas que podem ser utilizadas como estratégias para melhorar a segurança na terapia transfusional. Destes, três produziram checklists com a finalidade de assegurar que o procedimento de transfusão seja executado com segurança, sem omissão de nenhuma etapa. Os instrumentos foram desenvolvidos para preenchimento da equipe de enfermagem nas etapas sob sua responsabilidade. O diferencial é o público-alvo: um destina-se a pacientes pediátricos ${ }^{3}$, um para Unidade Intensiva Coronariana ${ }^{21}$ e outro para pacientes adultos ${ }^{18}$.

Os checklists foram construídos tendo por base revisões de literatura para a identificação dos itens que os compuseram. Esses itens foram divididos em cuidados de enfermagem pré-transfusional, transfusional e pós-transfusional. Os cuidados executados devem ser assinalados no decorrer do processo transfusional pelo profissional de enfermagem responsável ${ }^{3,18,21}$.

A validação dos instrumentos ocorreu pela avaliação de um comitê de especialistas e cálculo do Índice de Validade de Conteúdo (IVC). Mediante as sugestões dos juízes, realizaram-se reformulações no conteúdo, resultando na versão final ${ }^{3,18}$.

Quanto à estrutura dos checklists, houve variação entre os estudos. 0 primeiro ${ }^{18}$ contou com 47 itens divididos em 8 seções: checagem da solicitação de transfusão; dados complementares; identificação da amostra de sangue do receptor para testes pré-transfusionais (quando coletada pela equipe de enfermagem); avaliação pré-transfusional do receptor; transporte da bolsa de hemocomponente; conferência do cartão transfusional da bolsa a ser transfundida; verificação da bolsa do hemocomponente e ato transfusional.

O segundo ${ }^{21}$ foi composto por 17 itens, subdivididos nas três etapas de atuação da enfermagem no processo de transfusão: antes, durante e pós-transfusão. Na etapa antes da instalação do hemocomponente estão cuidados referentes à conferência da prescrição médica, verificação dos sinais vitais, orientação ao paciente e familiar, identificação do paciente e acompanhamento nos primeiros dez minutos de infusão. Durante a transfusão a ênfase é para a identificação de reações adversas e controle do tempo de infusão; já na pós transfusão para a aferição dos sinais vitais, evolução do procedimento e descarte do material ${ }^{21}$.

O terceiro ${ }^{3}$ foi constituído de 14 itens e 56 subitens distribuídos entre as etapas pré, peri e pós-transfusional. A etapa pré-transfusional foi composta por quatro itens (orientações de enfermagem pré-transfusional, conferência do hemocomponente, identificação da criança e pré-medicação); a transfusional com

Editora Unijuí - Revista Contexto \& Saúde - ISSN 2176-7114 - v. 21, n. 44, out./dez. 2021 
seis itens (verificação dos sinais vitais, acesso venoso, instalação do hemocomponente, monitoramento do paciente, tempo de infusão, suspeita de reação transfusional) e a pós-transfusional com quatro itens (verificação dos sinais vitais, verificação dos sinais vitais uma hora após o término da transfusão, registros e monitorização da criança por 24h após término da infusão) ${ }^{3}$.

Outra ferramenta produzida para a segurança do receptor de hemocomponentes avaliou o impacto da introdução de uma equipe transfusional em uma instituição de saúde 4 . Os profissionais que compõem a equipe (técnicos de laboratório) acompanham o processo de transfusão desde a coleta da amostra até o término da transfusão. Em comparação ao período anterior à instalação da equipe, houve aumento no número de notificações de reações transfusionais e na segurança transfusional. Isso foi possível a partir da correção de falhas na identificação de amostras, nas requisições de transfusão, na verificação dos sinais vitais e identificação dos pacientes. Esses cuidados reduziram o risco de reações graves por troca de amostras ou de pacientes ${ }^{4}$.

As pesquisas que produziram checklists ressaltaram que estes mostraram-se como uma tecnologia confiável para a melhoria da qualidade e da segurança no processo de transfusão ${ }^{3,18,21}$. Eles auxiliam na redução de erros por omissão e variação dos cuidados ${ }^{21}$.

Quanto ao estudo que avaliou a equipe transfusional, ressalta-se sua importância para a uniformização das condutas e a minimização de falhas nas etapas do ato transfusional ${ }^{4}$. Esta mostrou-se uma estratégia que proporciona mais segurança ao receptor, posto que permite que todos os procedimentos sejam seguidos, aumenta as notificações de eventos adversos, bem como favorece o reconhecimento e o desenvolvimento de estratégias de prevenção de reações transfusionais ${ }^{4}$.

\section{DISCUSSÃO}

Esta pesquisa buscou analisar a tendência das teses e dissertações brasileiras sobre a segurança no ato transfusional. Os resultados encontrados mostraram concentração de defesas e pesquisadores na região Sudeste do país. Verificou-se que, de acordo com a literatura, a maior produção científica foi realizada em universidades públicas, primordialmente as estaduais e federais, uma vez que estas são responsáveis pela maioria das atividades científicas no Brasil ${ }^{22}$.

Os estudos sobre a temática em questão são recentes. Acredita-se que o marco das produções possa ser atribuído à publicação da RDC no 57, em dezembro de 2010, pela Agência Nacional de Vigilância Sanitária (Anvisa), substituída pela RDC no 34, em 20147 . Esta estabeleceu a obrigatoriedade de notificação das reações relacionadas ao ato transfusional, forçando as instituições de saúde a criarem mecanismos para a identificação de eventos adversos ${ }^{4}$. Os dados resultantes das notificações são importantes, posto que identificam o perfil dos eventos adversos e possíveis estratégias de prevenção. Dentre elas, a ênfase aos cuidados durante o ato transfusional, às atividades educativas e à utilização de ferramentas que visem à promoção da segurança transfusional.

Editora Unijuí - Revista Contexto \& Saúde - ISSN 2176-7114 - v. 21, n. 44, out./dez. 2021 
Evidenciou-se a relevância da atuação dos profissionais de enfermagem na segurança transfusional, uma vez que foram os principais trabalhadores investigados entre as teses e dissertações analisadas. Todos os procedimentos pertinentes ao ato transfusional, exceto a prescrição (responsabilidade médica) e os testes pré-transfusionais (competência dos técnicos de laboratório), são de responsabilidade da equipe de enfermagem ${ }^{4}$.

Sendo assim, a equipe de enfermagem, além do conhecimento sobre a administração das transfusões, deve conhecer suas indicações, checar os dados para prevenção de erros, orientar os pacientes sobre a transfusão, identificar, comunicar e atuar na assistência às reações transfusionais, bem como realizar o registro de todo o processo ${ }^{20}$. Por ser responsável pela verificação final à beira do leito, a enfermagem é a última barreira capaz de detectar eventos potencialmente letais ${ }^{13}$. Entende-se que uma equipe com conhecimento e habilidades insuficientes pode favorecer a ocorrência de complicações e danos irreversíveis aos receptores de sangue.

O processo transfusional, desencadeado pela decisão médica de transfundir, compreende um conjunto de etapas, como a coleta de amostra do paciente para testes pré-transfusionais, a liberação do hemocomponente, a instalação e o monitoramento de reações adversas. Essa complexa rede de processos envolve interações entre profissionais de diversas categorias ${ }^{2}$. Diante disso, todos os profissionais envolvidos têm papel relevante na segurança transfusional. Assim, além da enfermagem, outras categorias profissionais devem ser exploradas em estudos acadêmicos, posto que também necessitam estar preparadas adequadamente, buscando reduzir os riscos à segurança da terapia transfusional.

Os achados das teses e dissertações a respeito da deficiência de conhecimento dos profissionais que atuam no ato transfusional, podem vir a comprometer a segurança transfusional|11,19-20. Um estudo verificou que os profissionais não se sentiam aptos a atuar em procedimento transfusional, considerando-se que não possuíam capacitação específica para este fim ${ }^{23}$. A transfusão de hemocomponentes demanda conhecimento e habilidade técnica, tendo em vista a prevenção de complicações e danos irreversíveis aos receptores ${ }^{13}$. Existe a possibilidade da ocorrência de eventos adversos preveníveis em todas as etapas do processo, desencadeados por falhas humanas ou de sistematização ${ }^{11}$.

Por exemplo, tem-se como principal causa de eventos adversos notificados a identificação incorreta dos pacientes, seguida por administração do hemocomponente errado (troca de paciente ou grupo $A B O$ incorreto) e identificação inadequada das amostras ${ }^{2}$. Com isso, percebe-se a importância de não subestimar a sequência das etapas propostas, já que a falha em uma etapa pode vir a ocasionar eventos adversos ao paciente.

Além disso, tem-se o desconhecimento pelos profissionais das diretrizes para transfusão de hemocomponentes, o qual torna-se um risco importante a ser evitado ${ }^{24}$. Por meio da identificação das fragilidades do conhecimento dos profissionais e das falhas observadas nos processos, é possível elencar as necessidades educativas a fim de reduzir possíveis erros transfusionais. Estratégias educativas podem contribuir para reduzir as indicações inadequadas de hemocomponentes, diminuir erros pré (coleta e identificação do paciente), trans

Editora Unijuí - Revista Contexto \& Saúde - ISSN 2176-7114 - v. 21, n. 44, out./dez. 2021 
(acompanhamento do paciente) e pós transfusionais (tratamento das reações) ${ }^{11}$, bem como promover o comprometimento do profissional na adesão aos procedimentos normatizados.

Os programas de hemovigilância internacionais asseveram que o maior risco para os receptores de uma transfusão de sangue é o erro humano. Existem várias razões para sua ocorrência no ambiente hospitalar. Estas podem incluir faIha de comunicação, falta de capacitação, lapsos de memória, desatenção, equipamentos defeituosos, fadiga, ignorância, condições de trabalho estressantes e outros fatores pessoais e ambientais ${ }^{2}$. Em atividades assistenciais que envolvem o fator humano, a ocorrência de erros é comum, entretanto é possível reduzir as possibilidades de ocorrência ${ }^{12}$.

Por esse motivo, os regulamentos técnicos são de extrema importância. Estes visam a padronizar as ações dos profissionais envolvidos nos procedimentos hemoterápicos com o objetivo de garantir a segurança e a qualidade na transfusão. A instauração de protocolos institucionais auxilia no direcionamento do processo transfusional ${ }^{23}$. Disponibilizar nas áreas de trabalho instruções para execução correta dos procedimentos de rotina pode ser uma estratégia para a redução dos erros, de forma a permitir menor variação entre as práticas ${ }^{4}$. A baixa adesão às normas, no entanto, pode contribuir diretamente para o aumento de falhas em todas as fases do ato transfusional ${ }^{23}$.

Ademais, a tendência ao uso de checklist na área da saúde é uma prática crescente nos diferentes cenários da assistência, que pode auxiliar de maneira positiva na segurança transfusional. Esse tipo de instrumento mostra-se como uma estratégia eficaz no combate aos eventos adversos e no aprimoramento da segurança do paciente ${ }^{18}$. Tem-se como exemplo o checklist de Cirurgia Segura, o qual foi insitituído pela OMS e contribuiu para a redução de complicações e mortes em procedimentos cirúrgicos ${ }^{25}$.

Nesse sentido, uma lista de verificação estabelece um roteiro que auxilia na prevenção de incidentes causados por falhas humanas ou de processo ${ }^{18}$. Compreendendo a relevância do ato transfusional, no qual um erro de checagem pode levar a um desfecho fatal e à existência de lacunas entre o conhecimento científico e a prática assistencial, a criação de tecnologias, como o checklist, tem significativa importância ${ }^{21}$. Evidenciou-se, entretanto, que os checklists relacionados ao ato transfusional são direcionados a uma população ou a uma etapa do processo em específico. Ou seja, não há um checklist que possa ser utilizado de maneira universal por todos os profissionais de saúde envolvidos no ato transfusional, o que evidencia uma lacuna do conhecimento.

Ressalta-se que o risco, associado à transfusão de sangue, poderia ser significativamente minimizado por meio da introdução de sistemas de qualidade, da educação e do treinamento dos profissionais ${ }^{9}$. Sendo assim, aliado à educação, é fundamental a utilização de ferramentas (protocolos, manuais, recursos didáticos, equipe transfusional, checklist) como barreiras de segurança para assegurar a execução de todos os procedimentos necessários em cada etapa do ato transfusional. 


\section{CONSIDERAÇÕES FINAIS}

Identificou-se como tendência o predomínio de dissertações, provenientes de Mestrado profissional, desenvolvidas em universidades federais, na Região Sudeste, no ano de 2019, tendo como população pesquisada os profissionais de enfermagem. Observaram-se duas vertentes na exploração do objeto de estudo - segurança no ato transfusional. Na primeira, as pesquisas avaliaram o conhecimento dos profissionais de saúde para atuação nos procedimentos hemoterápicos. Nela, verificou-se que o conhecimento dos profissionais responsáveis pelas etapas do ato transfusional é limitado. Esse fato pode comprometer ou se tornar uma ameaça à segurança do paciente, submetendo-o a um sério risco de receber hemocomponentes incorretos.

Na segunda, abordaram a utilização de ferramentas de melhoria da segurança no ato transfusional com ênfase na elaboração de checklists. A utilização de checklist é relevante na prática assistencial e muito importante no ato transfusional, uma vez que assegura a execução de todos os procedimentos estabelecidos, tendo como reflexo a qualidade na assistência e a segurança transfusional.

Observou-se, como limitações do estudo, a escassez de pesquisas, especialmente em âmbito de Doutorado. Algumas teses e dissertações não estavam disponíveis on-line na íntegra e houve o predomínio de estudos envolvendo profissionais de enfermagem em detrimento às demais categorias profissionais implicadas no processo de transfusão. Acredita-se que há necessidade de ampliar a avaliação do conhecimento das demais categorias profissionais envolvidas na terapia transfusional.

As evidências desta revisão sinalizam que a criação de programas de educação multiprofissionais e o desenvolvimento de estratégias, a exemplo dos checklists, que contemplem todas as etapas do procedimento, poderão incrementar a segurança no ato transfusional. Também profissionais qualificados e com suporte de ferramentas teórico-práticas têm potencial de contribuir para a redução dos riscos inerentes à terapia transfusional.

\section{REFERÊNCIAS}

${ }^{1}$ Brasil. Ministério da Saúde. Agência Nacional de Vigilância Sanitária. Marco conceitual e operacional da hemovigilância: guia para a hemovigilância no Brasil. Brasília: Anvisa; 2015. 77 p.

2 Teles AIS. Caracterização e avaliação do impacto dos erros nos serviços de medicina transfusional. Lisboa. [Dissertação de Mestrado em Gestão de Unidades de Saúde] Universidade Lusófona de Humanidades e Tecnologias; 2014.

${ }^{3}$ Bezerra CM. Construção e validação de checklist para transfusão sanguínea em crianças. Fortaleza, CE. [Dissertação de Mestrado em Enfermagem] - Universidade Federal do Ceará (UFC); 2017.

${ }^{4}$ Kropf AD. Impacto da implantação de uma equipe transfusional nas atividades de hemovigilância e na segurança transfusional do Hemonúcleo Costa Verde em Angra dos Reis, RJ. Ribeirão Preto, SP. [Dissertação de Mestrado Profissional em Hemoterapia e Biotecnologia] - Universidade de São Paulo; 2018.

${ }^{5}$ Brasil. Ministério da Saúde. Documento de referência para o Programa Nacional de Segurança do Paciente Brasília: Ministério da Saúde; 2014. 
${ }^{6}$ Brasil. Ministério da Saúde. Agência Nacional de Vigilância Sanitária. Resolução da Diretoria Colegiada RDC $n^{\circ} 36 / 13$. Institui ações para a segurança do paciente em serviços de saúde e dá outras providências. Brasília; 25 jul. 2013.

${ }^{7}$ Brasil. Ministério da Saúde. Agência Nacional de Vigilância Sanitária. Resolução da Diretoria Colegiada RDC $n^{\circ}$ 34/14. Dispõe sobre as Boas Práticas no Ciclo do Sangue. Brasília; 11 jun. 2014.

${ }^{8}$ Brasil. Ministério da Saúde. Portaria de consolidação № 5, de 28 de setembro de 2017. Consolidação das normas sobre as ações e os serviços de saúde do Sistema Único de Saúde. Brasília; 28 set. 2017.

${ }^{9}$ World Health Organization (WHO). Blood safety and availability. 2019. [Acesso em: 5 out. 2019]. Disponível em: https://www.who.int/news-room/fact-sheets/detail/blood-safety-and-availability

${ }^{10}$ Junior SRAM, Andrade NBS. Enfermeiro como protagonista na segurança transfusional no serviço de hemoterapia: uma revisão integrativa. Caderno de Graduação - Ciências Biológicas e da Saúde - Unit - Sergipe [internet]. 2020;6(1):89-98. [Acesso em: 26 abr. 2021]. Disponível em: https://periodicos.set.edu.br/cadernobiologicas/article/ view/7857

${ }^{11}$ Negrães RT. Avaliação da segurança em terapia transfusional nas unidades de terapia intensiva pediátrica e adulta do Hospital de Base Ary Pinheiro em Porto Velho/Rondônia: subsídios para um programa de treinamento em segurança transfusional e no uso racional de hemocomponentes. Porto Velho, RO. [Dissertação de Mestrado Profissional em Ensino em Ciências da Saúde] - Universidade Federal de Rondônia, 2014.

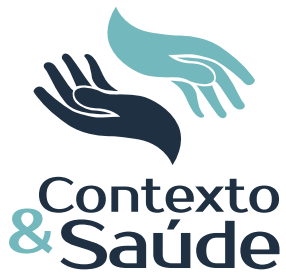

12 Bolton-Maggs PHB, Watt A. Human factors in SHOT error incidentes. The 2017 Annual SHOT Report. 2018. [Acesso em: 18 jun. 2019]. Disponível em: https://b-s-h.org.uk/ media/16506/shot-report-2017.pdf

${ }^{13}$ Bolton-Maggs PHB. Serious hazards of transfusion - conference report: celebration of 20 years of UK haemovigilance. Transfusion Medicine. 2017 dez.;27(6):393-400. doi: https://doi.org/10.1111/tme.12502

${ }^{14}$ Brasil. Agência Nacional de Vigilância Sanitária. Relatório de hemovigilância 2015. Brasília: Anvisa; 2016.

${ }^{15}$ Vosgerau DSAR, Romanowski JP. Estudos de revisão: implicações conceituais e metodológicas. Diálogo Educ. 2014;14(41):165-189. doi: http://dx.doi.org/10.7213/dialogo. educ.14.041.ds08

${ }^{16}$ Capes (Coordenação de Aperfeiçoamento de Pessoal de Nível Superior). Catálogo de Teses \& Dissertações. Brasília: Capes. 2018. [Acesso em: 18 jun. 2019]. Disponível em: http://catalogodeteses.capes.gov.br

${ }^{17}$ Brasil. Lei de Direitos Autorais no 9.610/1998 e normas correlatas. 4. ed. Brasília: Senado Federal, Coordenação de Edições Técnicas; 2015. 186 p.

${ }^{18}$ Vieira CMAS. Construção de um checklist para a prática transfusional segura beira-leito. Juiz de Fora, MG. [Dissertação de Mestrado em Enfermagem] - Universidade Federal de Juiz de Fora; 2019.

${ }^{19}$ Cherem EO. O conhecimento do enfermeiro sobre a hemotransfusão em unidade de terapia intensiva neonatal. Niterói, RJ. [Dissertação de Mestrado Profissional em Saúde Materno-Infantil] - Universidade Federal Fluminense; 2015.

${ }^{20}$ Tavares JL. Conhecimento dos profissionais da equipe de enfermagem de um hospital de ensino de Minas Gerais sobre hemotransfusão. Uberaba, MG. [Dissertação de Mestrado em Atenção à Saúde] - Universidade Federal do Triângulo Mineiro; 2013.

${ }^{21}$ Silva RH. Checklist de cuidados de enfermagem na hemotransfusão: estratégia para segurança do paciente em Unidade Intensiva Coronariana. Florianópolis, SC. [Dissertação de Mestrado Profissional em Gestão do Cuidado em Enfermagem] - Universidade Federal de Santa Catarina; 2019.

${ }^{22}$ Capes (Coordenação de Aperfeiçoamento de Pessoal de Nível Superior). GeoCapes. Brasília: Capes; 2019. [Acesso em: 27 abr. 2021]. Disponível em: https://geocapes.capes.gov.br/geocapes/

Editora Unijuí - Revista Contexto \& Saúde - ISSN 2176-7114 - v. 21, n. 44, out./dez. 2021 
23 Santos LX, Santana CCAP, Oliveira ASB. Hemotransfusion under the perspective of nursing care. Rev Fund Care On-line. 2021 jan./dez;13:65-71. doi: http://dx.doi. org/10.9789/2175-5361.rpcfo.v13.7458

${ }^{24}$ Bermúdez ZV, Ríos AC. Conocimiento de los profesionales enfermería sobre normativa de trasfusión de hemocomponentes. Enfermería Actual de Costa Rica [Internet]. 2018 dez. [citado 5 out. 2021];(35):128-143. Disponível em: http://www.scielo.sa.cr/scielo. php?script=sci_arttext\&pid=S1409-45682018000200128\&lng=en. doi: http://dx.doi. org/10.15517/revenf.v0i35.32747

${ }^{25}$ Ramsay G, Haynes AB, Lipsitz SR, et al. Reducing surgical mortality in Scotland by use of the WHO Surgical Safety Checklist. The British Journal of Surgery. 2019;106(8):10051011. doi: 10.1002/bjs.11151. 